\title{
Challenges of Membrane Technology in Biorefineries
}

\author{
Lukka Thuyavan Yogarathinam ${ }^{\mathrm{a}}$, Ahmad Fauzi Ismaila*, Pei Sean Goh ${ }^{\mathrm{a}}$, \\ Arthanareeswaran Gangasalam ${ }^{\mathrm{b}}$ \\ ${ }^{a} A d v a n c e d$ Membrane Technology Research Centre (AMTEC), Universiti Teknologi \\ Malaysia, 81310 UTM Johor Bahru, Johor, Malaysia \\ ${ }^{b}$ Membrane Research Laboratory, Department of Chemical Engineering, National \\ Institute of Technology, Tiruchirappalli 620 015, India
}

Submitted: 17/09/2020. Revised edition: 25/10/2020. Accepted: 08/11/2020. Available online: 19/11/2020

\begin{abstract}
Membrane separation processes have been deployed for downstream applications in biorefineries. This article discusses the challenges of membrane technology in purification of biofuels such as bioethanol, biodiesel and biogas. The significance of membrane technology are discussed towards the fractionation of lignocellulosic biomass for biofuel production. The membrane reactors for biodiesel production were also studied. Limitation with respect to each individual processes on biofuel purification were also reported. The major limitation in membrane separation are membrane fouling and concentration polarization. Membrane engineering and process optimization are the viable tools to enhance the performance of membrane. Recently, inorganic nanofillers has significant control in alteration of polymeric membrane characteristics for the improvement of permeability and selectivity. This article would be an insight for researchers to understand the challenges of biorefinery membrane separation.
\end{abstract}

Keywords: Biofuels, biorefineries, fouling, membrane modification, membrane technology

\section{INTRODUCTION}

Globally, depletion of fossil fuels and global warming have intensified the use of renewable biofuels as an alternative fuel by international energy agencies and governments. Biofuels are derived from low-cost feedstock materials such as algae, household waste, agricultural and woody biomass, etc. Major biofuels include bioethanol, biogas, biodiesel, etc. Downstream processing is a challenging task in biorefineries. Membrane technology has been deployed in biorefineries for the (i) separation of sugars from lignocellulosic biomass, (ii) separation of glycerol from biodiesel (iii) harvesting microalgae for bio-oil production, (iv) concentration of methane from agricultural anaerobic digesters, (v) recovery of bioethanol from fermentation broth, etc $[1,2]$. The advantage of membrane separation over conventional unit operations are superior product purity, versatile membrane processes, no phase change, lower energy demand, easy to scale up and low cost. However, membrane technology has limitation as membrane fouling in longer operation duration. It reduces the life span of membrane and efficiency of filtration. Concentration polarization is another type of fouling forms a solute layer over the membrane surface. To overcome these limitations, membrane modifications have been attempted to produce resilient membranes with high permeability. The studies on 
challenges faced by membrane technology in biorefineries are sparsely reported. Thus, this article aims to discuss the challenges in membrane processes for various biorefinery applications.

\section{LIGNOCELLULOSIC BIOMASS FILTRATION}

Lignocellulosic biomass is a plentiful renewable feedstock (forest and agricultural residues) that naturally occurs on the earth, which constitutes of cellulose, hemicellulose and lignin. Fermentable sugars are the required carbon source to produce second generation biofuel using microorganisms [3]. This process involves many complex steps including pre-treatment of lignocellulosic biomass and enzymatic hydrolysis to convert simple sugars, conversion of fermentable sugars into alcohols, and purification of biofuels. Upon pre-treatment, lignocellulose biomass generates value added chemicals and inhibitory compounds such as furfural and organic acids. In this instance, membrane technology has been utilized in separation of sugars from hydrolysed lignocellulosic biomass solution. The challenging task in this step is separation of fermentable sugars from similar size inhibitors. Besides, organic acids causes adverse fouling effect during filtration. This in turn affects the membrane performance and selectivity. The application of pressure driven membrane separation, membrane bioreactor and pervaporation process on bioethanol production from lignocellulose filtration are discussed below:

\section{PRESSURE DRIVEN MEMBRANE SEPARATION}

Ultrafiltration (UF) and nanofiltration (NF) membranes have been used to isolate lignin and inhibitors from different hydrolysed feed solutions (rice straw, sugarcane bagasse, wheat straw, spruce chips), respectively. [47]. The selection of UF and NF membranes in lignocellulose fractionation is based on the appropriate pore size required for separation of larger and smaller molecules, respectively. However, commercial membranes possess hydrophobic characteristics, which are prone to adsorption of lignocellulose occur during filtration of complex feed solution. Lignin's molecule size is in the range of a few hundred daltons, resulting in adsorption and aggregation above the surface of low pore-sized membranes. Lignin structure varies with respect to acid and alkaline hydrolysis, leading to lignin retention complexities. Moreover, the size of fermentable sugars and pre-treatment by-products are smaller and closer to one another. It ultimately leads to decrease the membrane selectivity. Besides, in the case of NF membranes, fouling of organic acids induce changes in membrane pore structures. To overcome fouling, novel membranes such as mixed matrix membranes, thin film nanocomposite membranes, electrospun nanofibrous membranes and ceramic membranes are used in the treatment of wide range of wastewater and seawater desalination. Such membrane modification allows impartation of unique properties like hydrophilicity and improving mechanical stability by incorporating nanofillers such as metal oxides, nano clay, carbon nanomaterials, biopolymers, and metal organic frameworks. Thin film nanocomposite polymeric NF membranes were also attempted for the separation for xylose from glucose [10]. Studies on optimization of hydrodynamic conditions such as feed $\mathrm{pH}$ and ionic strength also displayed 
significant influence in control of selective separation of fermentable sugars [8, 9]. For effective lignocelluloic biomass filtration, membrane surface modification can be focused upon to decrease the affinity between lignocellulose and membrane surface by various methods such as coating, grafting, blending and immobilisation of hydrophilic polymer and naofillers.

\section{MEMBRANE BIOREACTOR}

Membrane bioreactor (MBR) is the coupling of membrane separation and bioreactor to aid in the conversion of substrate into product through biocatalyst. MBR is a cost effective and single step method for fermentation and clarification processes. Microorganism or enzymes act as a catalyst. In bioethanol production, microfiltration $(\mathrm{MF})$ and UF membranes are used to enrich microbial cell concentration for higher productivity and elimination of secondary metabolites. In this process, the complex problem is the design of membrane module design and membrane selection. Biocatalytic membranes reactors and reverse membrane bioreactor are novel immobilization-based MBR configurations for biofuel productions. Zymomonas mobilis, Saccharomyces cerevisiae, and Pichia stipites are commonly utilized as microbial biocatalyst [11-13]. Laccase and cellulase are prominent enzymes used for hydrolysis of lignocellulosic biomass [14, 15]. In the above configurations, catalyst can are either immobilized on the membrane or suspended in the feed stock for quick conversion of substrate and enhance productivity. However, enzyme activity and reusability, substrate conversion rate and filtration mode are major determining factors in immobilized MBR. In addition to this, membrane fouling is also a significant drawback in continuous operations. In MBR, microbial population, extracellular polymeric substances, byproducts can attach on the surface as well as pore walls of low surface energy hydrophobic membrane. The larger molecular weight extracellular polymeric matrix initially attach on the surface of membrane and provides support to form biofilm formation through microbial colonies. It ultimately leads to decrease in membrane separation and deterioration of lifecycle. Cross flow velocity is a viable tuning parameter to control the attachment of cells on membrane surface. Besides, hydrophilic membrane incorporated with biocidal (silver and graphene oxide) nanoparticles showed potential in reducing biofouling [16]. A good choice of membrane for MBR intensification in biorefineries would be hydrophilic membrane with suitable biocatalyst immobilisation technique.

\section{PERVAPORATION}

Ethanol dehydration is the final step in biofuel purification after clarification of microbial cells. Pervaporation involves the recovery of ethanol from the fermentation broth, which is an alternative to traditional distillation method. Hydrophobic polydimethylsiloxane (PDMS) based polymeric membranes are used for the recovery of biofuel from fermentation broth [17, 18]. In pervaporation, membrane wetting and fouling are two common issues in filtration of fermentation broth. To overcome this issue, super hydrophobic membranes are utilized to improve permeability and selectivity of volatile organic compounds. Silane based modification and grafting of hydrophobic fluoropolymers would be a feasible 
and easy technique to obtain hydrophobic characteristics in polymeric membrane.

\section{BIODIESEL PURIFICATION}

Biodiesel is obtained from transesterification of oil sources such as vegetable oils, animal fats and long chain fatty esters. The common sources are soybean oil, canola oil, sunflower oil, cotton seed oil, waste vegetable oil, etc [19]. Transesterification can be achieved either by chemical or enzymatic method. In transesterification reaction, tryglycerides from oil reacts with alcohol to produce a fatty acid methyl ester and glycerol. The required characteristics should be of high purity fatty acid methyl ester (biodiesel), free of glycerol. UF membranes have shown promising potential as a low energy method for to extract glycerol from transesterification mixtures [20, 21]. Lipase based biocatalytic membrane reactor can also be utilized in biodiesel production [22]. Enzymatic conversion is a cost effective and energy efficient method for biodiesel production. However, membrane fouling and oil layer formation are limitations in industrial scale filtration. The oil molecules initially attaches on the top skin layer and blocks the pores upon pressure assisted filtration. To overcome these limitations, hydrophilic nanomaterials are used as a filler for the development of polymeric membranes. For efficient catalytic reaction, nanomaterial can also be used as a carrier for the immobilization of enzymes.

\section{BIO-OIL PRODUCTION}

Bio-oil production based on microalgae includes the growth and cultivation of microalgae, microalgae processing, and bio-oil extraction. The key advantage of microalgae in biodiesel production over other plant sources is that (i) it contains high amounts of triacylglycerides and (ii) large agricultural land is not needed [23]. In microalgae biorefineries, membrane technology plays a key role in the dewatering of algae reactor. Furthermore, membrane integrated photobioreactor are also used for cultivation of microalgae and separation of algal biomass. MF and UF membranes are applied in harvesting of microalgae. The harvested microalgae can be further used for the extraction of bio-oils in biodiesel production and value-added chemicals such as antioxidants, polyunsaturated fatty acids, proteins and polysaccharides. Upon filtration, extracellular organic material in microalgae suspension can attach to the membrane surface and decrease membrane-harvesting efficiency. To alleviate membrane fouling, novel membrane module designs and negatively charged polymeric membranes were attempted [24-26]. For dewatering of microalgae, low fouling osmotic driven membrane separation can be developed.

\section{BIOGAS PURIFICATION}

Biogas is derived from the decomposition of organic matter under anaerobic conditions. The sources of such organic matter is diverse, such as agricultural, sewage, food, municipal waste and manure waste. Biogas is a blend of gases such as methane $\left(\mathrm{CH}_{4}\right)$, carbon dioxide $\left(\mathrm{CO}_{2}\right)$ and traces of hydrogen sulphide $\left(\mathrm{H}_{2} \mathrm{~S}\right)$ [27]. The standard characteristic of biogas for fuel application should be of pure methane. In this regard, membrane technology has been deployed to concentrate methane from gaseous 
mixture. However, physical aging and plasticization are significant drawbacks faced by gas separation membranes. To overcome this, mixed matrix membranes, thin film nanocomposite membranes are developed and these membranes exhibit better gas permeability and selectivity for the separation of $\mathrm{CO}_{2} / \mathrm{CH}_{4}$. Inorganic fillers (carbon nanotubes, graphene oxide, covalent organic frameworks, metal organic frameworks, nano clays, zeolites and carbon molecular sieves) and $\mathrm{CO}_{2}$-philic functionalized nanomaterials also showed salient role in absorption of $\mathrm{CO}_{2}$. The main determining factor in design of gas separation membranes should be the inorganic filler used and polymer interaction, nanofiller size and agglomeration [28]. Agglomeration is a common issue in fabrication of both gas and liquid separation membranes at higher nanomaterial concentration. Functionalized nanomaterials were used for homogeneous dispersion in polymeric matrix. Overall, this article provides a brief overview of the pros and cons of membrane technology in biorefineries.

\section{FUTURE OUTLOOK}

- Intensification of membrane-based technology is required to explore the sustainable production of biofuels and biochemical valueadded products in biorefineries.

- Optimization of membrane process can also be attempted to alleviate fouling and scale up of large-scale biorefineries.

- Energy efficient hydrophilic fouling resistant membrane can be developed with respect to biorefineries products, using inorganic nanofillers. Indeed, grafting, coating and surface modification of membranes needs to consider for the enhancement of selectivity.

\section{REFERENCES}

[1] Y. He, D. M. Bagley, K. T. Leung, S. N. Liss, B. Q. Liao. 2012. Recent Advances in Membrane Technologies for Biorefining and Bioenergy Production. Biotechnol. Adv. 30: 817-858.

https://doi.org/10.1016/j.biotec hadv.2012.01.015.

[2] S. Curcio, G. De Luca, K. Saha, S. Chakraborty. 2016. Advance Membrane Separation Processes for Biorefineries. In: A. Figoli, A. Cassano, A. Basile (Eds.). Membr. Technol. Biorefining, Woodhead Publishing, Elsevier Ltd. 3-28. https://doi.org/10.1016/B978-008-100451-7.00001-3.

[3] J. N. Putro, F. E. Soetaredjo, S. Lin, Y. Ju, S. Ismadji. 2016. Pretreatment and Conversion of Lignocellulose Biomass Into Valuable Chemicals. RSC $A d v$. 6: 46834-46852. https://doi.org/10.1039/c6ra098 $51 \mathrm{~g}$.

[4] K. Servaes, A. Varhimo, M. Dubreuil, M. Bulut, P. Vandezande, M. Siika-aho, J. Sirviö, K. Kruus, W. PortoCarrero, B. Bongers. 2017. Purification and Concentration of Lignin From the Spent Liquor of the Alkaline Oxidation of Woody Biomass through Membrane Separation Technology. Ind. Crops Prod. 106: 86-96. https://doi.org/10.1016/j.indcro p.2016.10.005.

[5] Y. Li, B. Qi, Y. Wan. 2020. Separation of Monosaccharides from Pretreatment Inhibitors by 
Nanofiltration in

Lignocellulosic Hydrolysate: Fouling Mitigation by Activated Carbon Adsorption. Biomass and Bioenergy. 136: 105527. https://doi.org/10.1016/j.biomb ioe.2020.105527.

[6] V. Oriez, J. Peydecastaing, P. Y. Pontalier. 2019. Separation of Sugarcane Bagasse Mild Alkaline Extract Components by Ultrafiltration - Membrane Screening and Effect of Filtration Parameters. Process Biochem. 78: 91-99. https://doi.org/10.1016/j.procbi o.2019.01.006.

[7] R. Lakra, R. Saranya, Y. Lukka Thuyavan, S. Sugashini, K. M. M. S. Begum, G. Arthanareeswaran. 2013. Separation of Acetic Acid and Reducing Sugars from Biomass Derived Hydrosylate Using Biopolymer Blend Polyethersulfone Membrane. Sep. Purif. Technol. 118: 853861.

https://doi.org/10.1016/j.seppur. 2013.08.023.

[8] S. K. Maiti, Y. Lukka Thuyavan, S. Singh, H. S. Oberoi, G. P. Agarwal. 2012. Modeling of the Separation of Inhibitory Components from Pretreated Rice Straw Hydrolysate by Nanofiltration Membranes. Bioresour. Technol. 114: 419-427. https://doi.org/10.1016/j.biortec h.2012.03.029.

[9] S. C. Singh, Z. V. P. Murthy. $2017 . \quad$ Hemicelluloses Separation from Causticcontaining Process Stream by Ultrafiltration. Sep. Sci. Technol. 52: 2252-2261. https://doi.org/10.1080/014963 95.2016.1273952.
[10] K. H. Mah, H. W. Yussof, M. N. Abu Seman, A. W. Mohammad. 2019. Optimisation of Interfacial Polymerization Factors in Thinfilm Composite (TFC) Polyester Nanofiltration (NF) Membrane for Separation of Xylose from Glucose. Sep. Purif. Technol. 209: 211-222. https://doi.org/10.1016/j.seppur. 2018.07.041.

[11] F. Wirawan, C. Cheng, Y. Lo, C. Chen, J. Chang. 2020. Continuous Cellulosic Bioethanol Co-fermentation by Immobilized Zymomonas Mobilis and Suspended Pichia Stipitis in a Two-stage Process. Appl. Energy. 266: 114871. https://doi.org/10.1016/j.apener gy.2020.114871.

[12] D. S. Inloes, D. P. Taylor, S. N. Cohen, A. S. Michaels, C. R. Robertson. 1983. Ethanol Production by Saccharomyces cerevisiae Immobilized in Hollow-fiber Membrane Bioreactors. Appl. Environ. Microbiol. 46: 264-278.

[13] D. Thi, T. Nguyen, P. Praveen, K. Loh, 2018. Zymomonas Mobilis Immobilization in Polymeric Membranes for Improved Resistance to Lignocellulose-derived Inhibitors in Bioethanol Fermentation. Biochem. Eng. J. 140: 29-37. https://doi.org/10.1016/j.bej.20 18.09.003.

[14] J. Luo, B. Zeuner, S. T. Morthensen, A. S. Meyer, M. Pinelo. 2015. Separation of Phenolic Acids from Monosaccharides by LowPressure Nanofiltration Integrated with Laccase PreTreatments. J. Memb. Sci. 482: 83-91. 
https://doi.org/10.1016/j.mems ci.2015.02.022.

[15] J. J. Stickel, B. Adhikari, J. Pellegrino, D. A. Sievers. 2018. Continuous Enzymatic Hydrolysis of Lignocellulosic Biomass in a MembraneReactor System. J. Chem. Technol. Biotechnol. 93: 21812190. https://doi.org/10.1002/j.

[16] M. Aslam, R. Ahmad, J. Kim. 2018. Recent Developments in Biofouling Control in Membrane Bioreactors for Domestic Wastewater Treatment. Sep. Purif. Technol. 206: 297-315. https://doi.org/10.1016/j.seppur. 2018.06.004.

[17] S. S. Gaykawad, Y. Zha, P. J. Punt, J. W. van Groenestijn, L. A. M. van der Wielen, A. J. J. Straathof. 2013. Pervaporation of Ethanol from Lignocellulosic Fermentation Broth. Bioresour. Technol. 129: 469-476.

https://doi.org/10.1016/j.biortec h.2012.11.104.

[18] D. J. O'Brien, G. E. Senske, M. J. Kurantz, J. C. Craig. 2004. Ethanol Recovery from Corn Fiber Hydrolysate Fermentations by Pervaporation. Bioresour. Technol. 92: 15-19. https://doi.org/10.1016/j.biortec h.2003.08.003.

[19] K. Y. Wong, J. H. Ng, C. T. Chong, S. S. Lam, W. T. Chong. 2019. Biodiesel Process Intensification through Catalytic Enhancement and Emerging Reactor Designs: A Critical Review. Renew. Sustain. Energy Rev. 116: 109399. https://doi.org/10.1016/j.rser.20 19.109399.
[20] M. Peyravi, A. Rahimpour, M. Jahanshahi. 2015. Developing Nanocomposite PI Membranes: Morphology and Performance to Glycerol Removal at the Downstream Processing of Biodiesel Production. J. Memb. Sci. 473: 72-84. https://doi.org/10.1016/j.mems ci.2014.08.009.

[21] M. C. S. Gomes, P. A. Arroyo, N. C. Pereira. 2015. Influence of Oil Quality on Biodiesel Purification by Ultrafiltration, $J$. Memb. Sci. 496: 242-249. https://doi.org/10.1016/j.mems ci.2015.09.004.

[22] A. L. Machsun, M. Gozan, M. Nasikin, S. Setyahadi, Y. J. Yoo. 2010. Membrane Microreactor in Biocatalytic Transesterification of Triolein for Biodiesel Production, Biotechnol. Bioprocess Eng. 15: 911-916.

https://doi.org/10.1007/s12257010-0151-7.

[23] S. M. Badenes, F. C. Ferreira, J. M. S. Cabral. 2013. Membrane Bioreactors for Biofuel Production. In: and B. V. R. Shri Ramaswamy, Hua-Jiang Huang (Ed.). Sep. Purif. Technol. Biorefinerie, John Wiley \& Sons, Ltd.

[24] A. K. S. Lau, M. R. Bilad, N. A. H. M. Nordin, K. Faungnawakij, T. Narkkun, D. K. Wang, T. M. I. Mahlia, J. Jaafar. 2020. Effect of Membrane Properties on Tilted Panel Performance of Microalgae Biomass Filtration for Biofuel Feedstock. Renew. Sustain. Energy Rev. 120: 109666.

https://doi.org/10.1016/j.rser.20 19.109666.

[25] L. T. Yogarathinam, A. Gangasalam, A. F. Ismail, P. 
Parthasarathy. 2018. Harvesting of Microalgae Coelastrella sp. FI69 using Pore Former Induced $\mathrm{TiO} 2$ Incorporated PES Mixed Matrix Membranes. J. Chem. Technol. Biotechnol. 93: 645655.

https://doi.org/10.1002/jctb.549 5.

[26] R. Huang, Z. Liu, B. Yan, Y. Li, H. Li, D. Liu, P. Wang, F. Cui, W. Shi. 2020. Layer-by-layer Assembly of High Negatively Charged Polycarbonate Membranes with Robust Antifouling Property for Microalgae Harvesting. $J$. Memb. Sci. 595: 117488. https://doi.org/10.1016/j.mems ci.2019.117488.
[27] B. Bharathiraja, T. Sudharsana, J. Jayamuthunagai, R. Praveenkumar, S. Chozhavendhan, J. Iyyappan. 2018. Biogas Production - A Review on Composition, Fuel Properties, Feed Stock and Principles of Anaerobic Digestion. Renew. Sustain. Energy Rev. 90: 570-582. https://doi.org/10.1016/j.rser.20 18.03.093.

[28] S. Basu, A.L. Khan, A. Canoodena. 2010. Membrane-based Technologies for Biogas Separations. Chem. Soc. Rev. 39: 750-768. https://doi.org/10.1039/b81705 0 a. 